\title{
THERMAL IMAGING IMPROVES THE ACCURACY OF FORENSIC MEDICAL EXAMINATION OF LIVING PERSONS WITH BRUISES OF SOFT TISSUES
}

\author{
by A. Urakov*, K. Ammer*, N. Urakova*, E. Fisher", L. Chernova*
}

* Izhevsk State Medical Academy, Metallistov str., 33-9. 426054, Izhevsk, Russia, urakoval@live.ru

** Medical Imaging Research Unit, University of South Wales, Pontypridd, UK, KAmmer1950@aol.com

\section{Abstract}

Proposed to monitor the temperature of the bruise to diagnose the presence, shape and size of zone of local hyperthermia, which is a promising test for the forensic medical examination the severity of the injury and determining the track-imprint left by a hard blunt object. Further research is warranted. bruising.

Key words: temperature, bruise, hemorrhage, inflammation, soft tissue injury, forensic medicine, bleach

At the same time, in official and scientific literature bruising continue to be regarded as unequivocal marks of injury and damage soft tissues [1]. However, to date there is no standard for treatment of bruises and proposed only one drug developed specifically as bleach bruising [2]. In addition, it is still not examined the relationship between the color change and the dynamics of the temperature of the skin in a bloodless closed soft tissue injury, on the one hand, and hemorrhage without tissue damage, on the other hand. Moreover, it is still not clarified the relationship between hemorrhage, bruising and inflammation of the soft tissues in closed injuries [3].

Results of our investigations considerable differences in the dynamics of color and temperature of skin in places intradermal hemorrhages resulting from injection of venous blood or venous bleeding on the one hand, and, on the other hand, in places strong pinch skin with fingers or blows with police baton.

Discovered that the injection of venous blood and interstitial venous bleeding leads to immediately formation growing blue spots in the skin at the injection sites in which a local temperature is not different from the temperature of the surrounding skin. Pinches and blows leads to immediately formation not growing red spots in the skin at the damages site, in which the local temperature exceeds the temperature of the surrounding skin. In other words, damages spots that appeared only resulting from saturation of the subcutaneous fat and skin venous blood, leaves a mark on the skin in the form of blue "cold" bruises. A damages spots resulting from the crushing of soft tissues, leaves a mark on the skin in the form of bright red "hot" bruises.

Found that 1 minute after was pinched skin temperature in the area of damage exceeds the temperature of the neighboring areas by $1.0-1.2^{\circ} \mathrm{C}$. Then after 5 minutes the temperature in this area is warmer than the adjacent areas of $1.5-5.0^{\circ} \mathrm{C}$ and remains at this level $100-120$ minutes. There is nothing surprising in the fact that all areas of local hyperthermia had different forms and different meanings of elevated temperature (Figure 1).

The fact that each pinch was performed by pressure exerted on the skin by the fingertips 6 different fingers ( 3 fingers of the left hand and 3 fingers of the right hand). All fingertips of hands have different size and different area of contact with the skin of a volunteer, so couldn't create the same pressure inside the skin, wich they squeezed. So the skin got different damage under the pad of each finger. Each of the 6 areas of local hyperthermia, comprising a total area of hyperthermia on each nip is a geometric figure that represents the track-imprint each of the 6 pads of the fingers, which had suffered damage. In addition, all individual sections of local hyperthermia for its location corresponded exactly to the places of application of the pressure force of each of the 6 fingers.

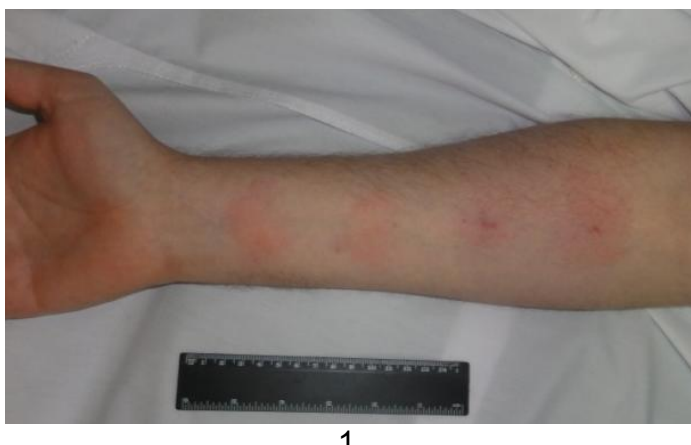

1

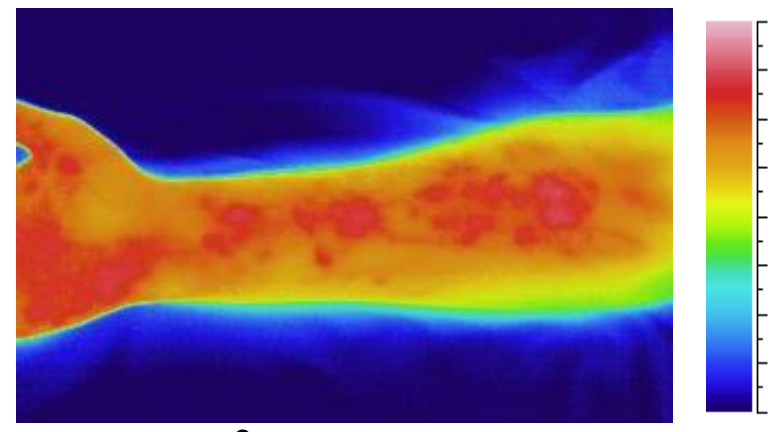

2

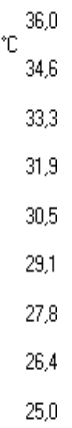

Figure 1. Forearm volunteer 45 minutes after being crushed in 4 areas of the skin pinches with the help of fingers in the visible (1) and infrared radiation tissue (2).

Similar results were obtained when venous bleeding because injection needle punctures the saphenous veins and when venous blood in volume $0.5 \mathrm{ml}$ was injecting intradermally the forearm and when in volume $0.1 \mathrm{ml}$ was injecting intradermally in the thigh. Namely, the skin at the site of skin puncture immediately lost its natural color and become blue. Blue skin had rounded and quickly increased in its size. In particular, 10 minutes after injection puncture of a vein in the forearm it was a stain in the shape of an ellipse with a maximum length of $9.2 \pm 0.4$ and width of $8.3 \pm$ $0.2 \mathrm{~cm}(\mathrm{P} \leq 0.05, \mathrm{n}=5) .10$ minutes after intradermal injection of $0.5 \mathrm{ml}$ of blood in the forearm skin blue also had an 
elliptical shape with a maximum length of $10.7 \pm 0.5$ and a width of $9.7 \pm 0.4 \mathrm{~cm}(P \leq 0.05, n=5)$. 10 minutes after 4 intradermal injections of $0.1 \mathrm{ml}$ of venous blood in the anterior surface of the femur in a patient in a coma, skin blue was in the form of circles with a diameter of $0.9 \pm 0.01 \mathrm{~cm}(P \leq 0.05, n=4)$. Moreover, the skin in the area of all these bruises remained normal temperature from the first moment and throughout all subsequent days until the complete disappearance of bruises.

Our results showed that immediately after the injection of venous blood into the skin or immediately after the injury injection needle superficial veins in the skin at the puncture spot appears blue. Then this blue spot in the skin continuously increases in size in all directions and 10 minutes later the site of a bruise over the initial size tenfold. Probably in this period occurs the skin permeation of venous blood. Because venous blood is cherry-blue, bloodsoaked patch of skin turning blue. The area of the bruise is constantly growing in size, and the temperature of the skin in the area of the bruise is not different from the temperature of the neighboring areas of the body (Figure 2).

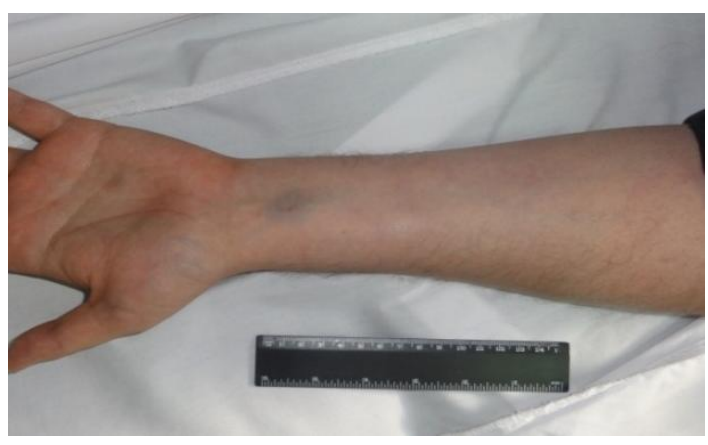

1

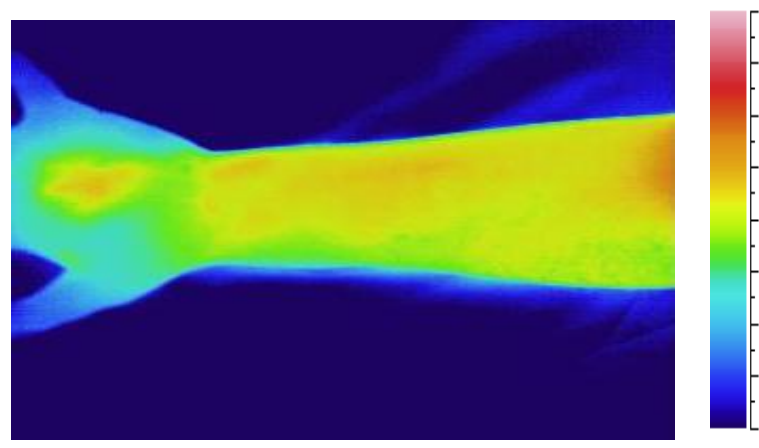

2

Figure 2. Forearm volunteer 10 minutes after intradermal injection of $0.5 \mathrm{ml}$ of its venous blood in the visible (1) and in the infrared (2) the range of the radiation spectrum of tissues.

In other words, after intradermal outpourings of venous blood in the skin was covered with bruises, so it seemed that in the forearm there are soft tissue injuries. However, the study of local skin temperature in these places showed the absence of local hyperthermia. It seemed a miracle: on the eye it was evident that in the forearm there are bruises that are traditionally considered evidence of soft tissue damage, but the camera shows the opposite, namely in the forearm there are no plots of local hyperthermia. That is, there is no symptoms of irritation, no inflammation, and therefore, no soft tissue damage !

Consequently, our own venous blood has no local irritant effect, so the blood is safe for our tissues and therefore venous blood can seep into the skin and subcutaneous fat without causing irritation and inflammation.

The obtained results allow to recommend infrared thermography carried out with a thermal imaging camera, to improve the quality of forensic examination of closed injuries of soft tissues in living persons with bruises hard blunt objects and in patients with injections of medicines. In addition, the camera allows you to shoot a film about the dynamics of change in temperature and skin color in the selected portion of the human body, which, in turn, can be archived by using flash memory and may be an additional document about the state of health investigated.

\section{REFERENCES}

[1] Viter VI, Vavilov AYu, Urakov AL, Chirkov SV. Infrared thermometry for assessing the onset of mechanical trauma that resulted in bruises or abrasions in living persons. Thermology International 2014; 2: $56-58$.

[2] Urakov AL, Urakova NA, Chernova, LV, Fisher EL. Bleach bruising. RUS Patent № 2539380. Bull $2015 ; 2$.

[3] Urakov A.L., Ammer K., Urakova N.A., Chernova L.V., Fisher E.L. Infrared thermography can discriminate the cause of skin discolourations. Thermology international. 2015. Vol. 25. N. 4. P. $209-215$. 